Voix et Images

voixetimages

\title{
Table des matières du volume VIII
}

Volume 8, numéro 3, printemps 1983

Jacques Ferron

URI : https://id.erudit.org/iderudit/200417ar

DOI : https://doi.org/10.7202/200417ar

Aller au sommaire du numéro

Éditeur(s)

Université du Québec à Montréal

ISSN

0318-9201 (imprimé)

1705-933X (numérique)

Découvrir la revue

Citer ce document

(1983). Table des matières du volume VIII. Voix et Images, 8(3), 581-583.

https://doi.org/10.7202/200417ar d'utilisation que vous pouvez consulter en ligne.

https://apropos.erudit.org/fr/usagers/politique-dutilisation/ 


\section{Table des matieres du volume VIII}

ANDRÉS, Bernard: “Post-mortem pour l'Eskabel?", 1, pp. 147-148; "Rouge sang et eau", 2, pp. 379-380; "Le prêchi-précha du nouveau masculinisme", 3, pp. 523-524.

BELLEAU, André: "La démarche socio-critique au Québec", 2, pp. 299-310.

BERTHIAUME, Pierre: "Charlevoix et Challe: regards sur les Anglais ou I'histoire au service d'idéologies antagonistes", 1, pp. 83-96.

BISHOP, Neil B.: "Vers une mythologie de la renaissance: /e Saint-Elias", 3, pp. 455-464.

BLANCHETTE, Louise: "Bibliographie de Réjean Ducharme" (en collaboration), 3 , pp. 535-567.

BOIVIN, Aurélien: "Bibliographie de Marie-Claire Blais" (en collaborationl, 2, pp. 249-295.

BOULANGER, Madeleine: "Madeleine Gagnon: Les constantes d'une écriture", 1, pp. 45-51.

BROCHU, André: "En état de poessie", 1, pp. 159-167; "Pósie et protéines", 2, pp. 362-369; "Des femmes et des mots", 3, pp. 503-510.

CANTIN, Pierre: "Bibliographie sélective de Jacques Ferron", 3, pp. $465-473$.

CLICHE, Elène: "Un rituel de l'avidite", 2, pp. 229-248.

DESJARDINS, Louise: "La lettre de l'amour et la crise du coeur", 1, pp. 35-43.

DUMAS, Céline: "Bibliographie de Réjean Ducharme" (en collaboration), 3, pp. 535-567.

DUQUETTE, Jean-Pierre: "Les nouveaux Écrits du Canada francais", 1, pp. 149-151:

"André Kertész: I'oeil à l'affut", 2, pp. 347-349; "Le legs Morrice au M.B.A.", 3, pp. 525-527.

FRÉMONT, Gabrielle: "Madeleine Gagnon: du politique à l'intime", 1, pp. 23-34.

FILTEAU, Claude: "Saint-Denys Garneau et Gauvreau, begues et ventriloques", 1. pp. 127-143.

GARCIA-MENDEZ, Javier: "Les romanciers du XXe face à leurs romans", 2, pp. 331-349.

HAECK, Philippe: "La fondation fantastique", 3, pp. 427-435.

HEBERT, Pierre: "Vers une typologie des analepses", 1, pp. 97-109.

LAFLECHE, Guy: "L'édition critique de Maria Chapdelaine par Ghislaine Legendre", 1. pp. 61-82.

LA MOTHE, Jacques: "Le Théatre et l'État au Québec", 3, pp. 519-521.

LAPIERRE, Carol: "Un désir mauve", 3, pp. 495-499.

LEVESQUE, Gałtan: "Regards lucides sur la sociéte", 1, pp. 154-158: "La revue des revues", 1, pp. 173-178; 2, pp. 383-388; 3, pp. 569-573. 
L'HERAULT, Pierre: "L'écrivain est un cénobite" (entrevue en collaboration), 3, pp. 397-405.

MAJOR (-LAPIERRE), Ruth: "Percer le mur du son du sens" (entrevue en collabora tion), 2, pp. 5-21; "Bibliographie de Marie-Claire Blais" (en collaboration), 2, pp. 249-295.

MANSEAU, Édith: "Bibliographie de Réjean Ducharme" (en collaboration), 3, pp. 535-567.

MARCOTTE, Gilles: "Marie-Claire Blais: je veux aller le plus loin possible" (entrevue), 2, pp. 191-209.

MELANCON, Benoit: "Yvon Boucher, Morceaux moisis: Essais en journalisme litté raire", 1, pp. 152-153.

MICHON, Jacques: "Notes bibliographiques", 1, pp. 179-180; 3, pp. 575-576; "La tentation de l'absurde chez Langevin et Languirand", 2, pp. 353-355; "La littérature selon Saint-Sulpice et Gerard Tougas", 3, pp. 511-513.

MINASSIAN, Chaké: "La littérature québécoise pour la jeunesse: acquis et perspectives", 2, pp. 357-359; "Signes avant-coureurs", 3, pp. 529-532.

MONETTE, GuY: "Les Poetes de la Confédération dans les Confitures de coings de Jacques Ferron", 3, pp. $421-426$.

OUELLET, Réal: "Brève réponse à une longue diatribe de Guy Laflèche suir une réédition récente de Maria Chapdelaine", 3, pp. $477-483$.

PELLETIER, Jacques: "Renaissance du roman social?", 2, pp. 371-377: "L'écrivain est un cénobite" lentrevue en collaborationl, 3, pp. 397-405; "De la Nuit aux Confitures de coings: le poids des événements d'Octobre 1970", 3, pp. 407-420.

ROBERT, Lucie: "Percer le mur du son du sens" (entrevue en collaboration), 1, pp. 5-21; "Bibliographie de Marie-Claire Blais" len collaboration), 2, pp. 249-295.

SLAMA, Beatrice: "La Belle Bete ou la double scène", 2, pp. 211-228.

SMITH, Donald: "Jacques Ferron et les écrivains", 3, pp. 437-453.

THERIEN, Gilles: "La BAte lumineuse ou le gibier imprévu", 1, pp. 168-169; "Une Quorantaine de jécistes", 2, pp. 351-352.

VANASSE, André: "Le Dictionnaire des oeuvres littéraires du Québec: l'événement de la décennie", 3, pp. 515-517.

VIGNEAULT, Robert: "L'essai québécois: préalables théoriques", 2, pp. 311-329.

WHITFIELD, Agnès: "Prochain épisode ou la confession manipulée", 2, pp. 111-126: "L'auteur implicite dans Trente arpents: modes de présence et signification narrative", 3, pp. 485-494.

\section{Erratum}

Dans l'article "Vers une typologie des analepses" de Pierre Hébert, Volume VIII, numéro I, se sont malheureusement glissées quelques erreurs que nous tenons à corriger:

- Á la sixième ligne du premier paragraphe de la page 102 ainsi qu'à la quatrième ligne du deuxième paragraphe de la page 103, il fallait lire analepse(s) et non analyse(s).

- A la page 108, le tableau aurait do être reproduit de la facon suivante: 


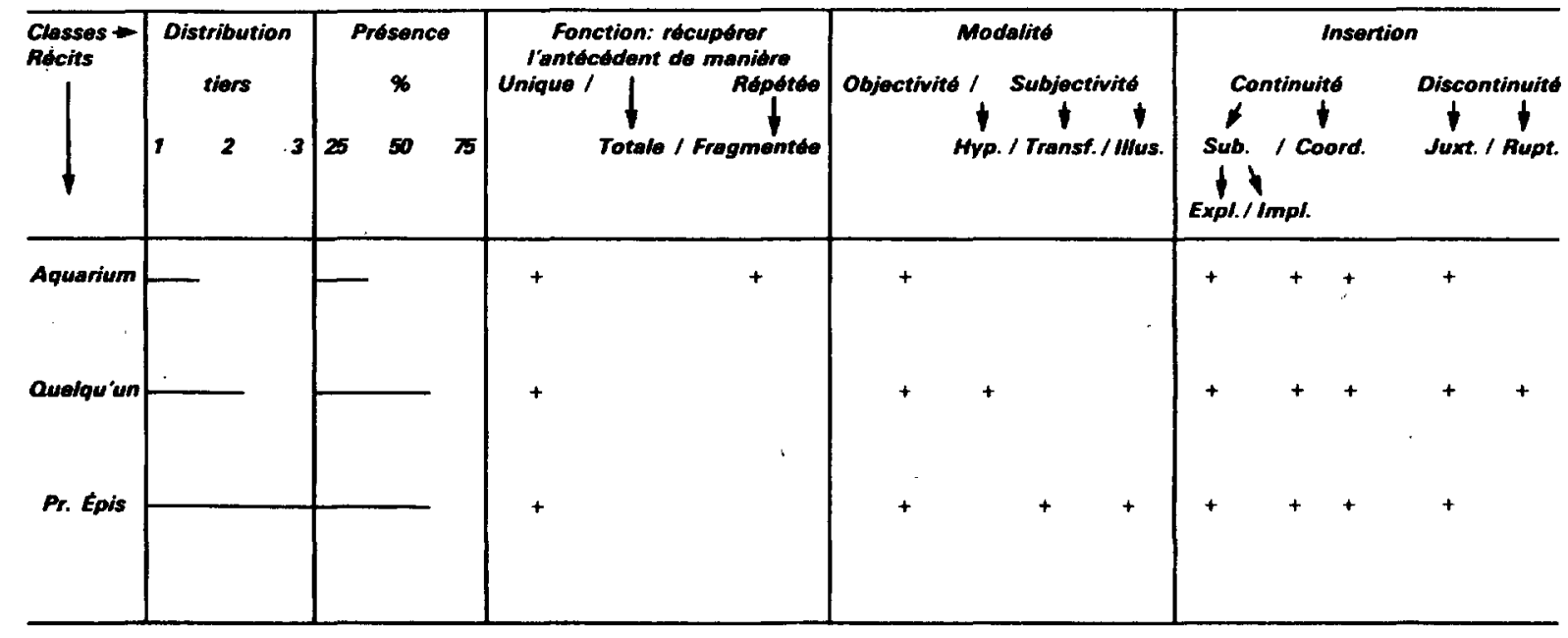

